\title{
GSTP1, GSTM1 and GSTT1 genetic polymorphisms and total serum GST concentration in stable male COPD
}

\author{
IRENA ŽUNTAR ${ }^{*}$ \\ ROBERTA PETLEVSKI ${ }^{1}$ \\ SLAVICA DODIG ${ }^{2}$ \\ SANJA POPOVIĆ-GRLE ${ }^{3}$ \\ 1 University of Zagreb, Faculty of \\ Pharmacy and Biochemistry, Zagreb \\ Croatia \\ 2 Children's Hospital Srebrnjak \\ Referral Centre for Clinical Paediatric \\ Allergology of the Ministry of Health \\ and Social Welfare, Zagreb, Croatia \\ ${ }^{3}$ University Hospital for Pulmonary \\ Diseases Jordanovac, Zagreb, Croatia
}

Accepted Occtober 3, 2013

\begin{abstract}
The aim of this study was to test the hypothesis that glutathione-S-transferase (GST) genotypes were associated with COPD. GSTP1, GSTM1 and GSTT1 genotypes were determined by DNA methods and GST activity spectrophotometrically in older male Caucasian Croats (non-smokers, ex-smokers, and smokers) with stable COPD $(n=30)$ and sex/age matched controls $(n=60)$. The distribution of GSTP1 genotypes and alleles in controls vs. COPD showed a statistical difference $(p<0.05)$. The odds ratio of CC/CT+TT (wild type GSTP1 exon 6 vs. joint heterozygous and mutant homozygous GSTP1 exon 6) was 10.000 and statistically different $(p=0.002)$. In this study, the GSTP1 mutant genotype of exon 5 (GG), as well as GSTP1 mutant and heterozygous genotypes of exon 6 (TT and $\mathrm{CT}$ ), were suggested to be genetic contributors to COPD susceptibility. Null GSTM1, null GSTT1 and joint GSTM1/GSTT1 null genotypes were not disease associated. Serum GST was not associated with GST genotypes and COPD or smoking history in our study subjects. Conclusions drawn from the study should be further supported and clarified by studies with larger sample sizes.
\end{abstract}

Keywords: glutathione S-transferases (GST), polymorphism, COPD, alpha-1-antitrypsin, lactate dehydrogenase

Chronic obstructive pulmonary disease (COPD) is a common preventable and treatable disease characterized by persistent airflow limitation, which is usually progressive and associated with an enhanced chronic inflammatory response to noxious particles or gases in the airways and the lung. COPD is a leading cause of morbidity and mortality worldwide and is more prevalent in smokers, in those over 60 years of age and in men more than in women (1).

Cigarette smoking is the best-studied COPD risk factor (2), but not all people with the same smoking history will develop COPD, due to differences in genetic predisposition to the disease. The best documented genetic risk factor is deficiency of alpha-1-

\footnotetext{
* Correspondence; e-mail: izuntar@pharma.hr
} 
I. Žuntar et al:: GSTP1, GSTM1 and GSTT1 genetic polymorphisms and total serum GST concentration in stable male COPD, Acta Pharm. 64 (2014) 117-129.

-antitrypsine (AAT) (1). Nowdays, there is increasing evidence that the development of COPD may be associated with the genetic variation in the xenobiotic-metabolizing enzymes such as microsomal epoxide hydrolase (mEPHX), glutathione S-transferases (GSTs), heme oxygenase-1 (HO-1), catalase (CAT), superoxide dismutase (SOD) and cytochrome P450 (CYP) (3).

GSTs are a large family of enzymes participating in detoxification of endogenous and environmental xenobiotics (4).

GSTM1 is involved in the metabolism of diol epoxides stemming from polycyclic aromatic hydrocarbons (PAHs) and ROS (5). GSTT1 can detoxify methylating agents, pesticides and many chemicals present in cigarette smoke (6). Null genotypes of GSM1 and GSTT1 result in a complete lack of the corresponding enzyme activities. GSTP1 shares some substrate specificity with GSTM1, being active towards many PAH epoxides, including benzo(a)pyrene (5). Several polymorphisms have been detected in the GSTP1 gene, including C341T (Ala114Val) substitution in exon 6 and A313G (Ile105Val) substitution in exon 5, resulting in an altered enzyme activity (7).

Many studies have reported on the association between GST gene polymorphisms and pulmonary disorders but with controversial results (8-14). Also, marked intra- and inter-ethnic differences in frequencies of common GST mutations have been revealed by many studies $(5,7,9,12,13,15,16)$. However, the association of GST genotypes and GST enzyme activity in COPD (17) is not thoroughly investigated yet.

The aim of our study was to determine GSTP1, GSTM1 and GSTT1 polymorphism distribution in a group of elderly men diagnosed with stable COPD and sex/age matched controls and to investigate the association between GST genotypes and COPD. Also, serum GST activity was investigated in connection with GST genotypes and smoking history.

\section{EXPERIMENTAL}

\section{Subjects}

A total of 90 subjects were included in the study. The first group, serving as the control, comprised a total of 60 healthy male subjects (mean age $63 \pm 5$ ), out of which 19 were non-smokers (31\%), 16 (27\%) ex-smokers who stopped smoking before 1-32 years before, and 25 current life-long smokers $(42 \%$, pack per year $=36.2 \pm 9.4)$. Upon approval issued by Ethics Committee of the University Hospital for Lung Diseases (Zagreb, Croatia), all subjects signed an informed consent prepared in line with the Helsinki Declaration, and filled out a structured questionnaire answering questions about their smoking habits, blood pressure and possible co-morbidities. Individuals suffering from renal, cardiac, gastrointestinal, endocrine and liver diseases, as well as those suffering from hypertension and asthma, were excluded from the study, and so were the subjects on any drug and/or vitamin/mineral therapy and alcoholics (consuming $>50 \mathrm{~g}$ of alcohol per day). The same holds for the subjects taking calcium antagonists, diuretics, laxatives and 
I. Žuntar et al.: GSTP1, GSTM1 and GSTT1 genetic polymorphisms and total serum GST concentration in stable male COPD, Acta Pharm. 64 (2014) 117-129.

antibiotics. Inclusion merits were based on standard blood and urine biochemistry, as well as on spirometry results which was unanimously required to be normal.

The second group included 30 male COPD patients (mean age $65 \pm 7$ ) treated at the Jordanovac University Hospital for Pulmonary Diseases, adjudicated to be stable for at least 3 months and needing no hospitalization and/or therapy modification. Their medication therapy, lasting 1-7 years, consisted of a combination of long-acting (salbutamol, 100-1000 $\mu \mathrm{g}$ ) and short-acting (salmeterol, $2 \times 50 \mu \mathrm{g}$ ) beta ${ }_{2}$-agonists as required, as well as administration of an anticholinergic or parasympatholytic (ipatropium bromide, 40-200 $\mu \mathrm{g}$ ) agent and one of the xantine preparations (Teolin $300 \mathrm{mg}, 2 \times 1$, or Teotard, 200-350 mg bid). All COPD subjects were without oral corticosteroids. The COPD group included patients (smokers and ex-smokers, pack per year $=42 \pm 15$, only four non-smokers) having $\mathrm{FEV}_{1}$ of $46.6 \pm 12.1 \%, \mathrm{FEV}_{1} / \mathrm{FVC}<0.7$, classified as COPD grade II (moderate) or III (severe) according to the Global Initiative for Chronic Obstructive Lung Disease (GOLD) standards (1). Twelve patients (40\%) were former smokers who stopped smoking before 5-46 years, 14 (46\%) were current life-long smokers, while $4(14 \%)$ had never smoked at all. COPD patients with coexisting renal, hepatic, endocrine or gastrointestinal diseases, and those taking $>50 \mathrm{~g}$ of alcohol daily, were excluded from the study. No significant difference was found between healthy smokers and COPD smokers in respect to the number of cigarettes consumed per year (pack per year).

In all study subjects recruited in one year, blood samples were collected between 7:00 and 9:00 a.m. after overnight fasting. The serum was separated by means of $2000 \times g$ 10 -minute centrifugation, and stored at $-20{ }^{\circ} \mathrm{C}$ until analysis. Spirometry was performed on the same day.

\section{Biochemical analysis of GST and LDH activity and AAT concentration}

Genomic DNA was extracted from whole blood samples using a modified salting-out procedure (19). Glutathione S-transferase (GST) and lactate dehydrogenase (LDH) activity, along with alpha-1-antitrypsin (AAT) concentration, were determined in serum samples of all subjects. LDH activity was measured using the standard method and available tests (Olympus Diagnostica $\mathrm{GmbH}$, Ireland) intended for Olympus AU 400 auto-analyzer. AAT concentration was determined by means of the radial immune-diffusion (RID) technique using commercially available standard and mono-specific anti-sera (Berinwerke AG, Germany). Serum GST activity was determined using the spectrophotometric method described by Habdous et al. (20), on a Trace spectrophotometer (Trace Scientific Ltd, Australia) utilising 1-chloro-2,4-dinitrobenzene (CDNB, Sigma) as a substrate.

\section{Determination of GSTP1, GSTM1 and GSTT1 genetic polymorphisms}

A313G and C341T GSTP1 gene polymorphisms were determined using the polymerase chain reaction-restriction fragment length polymorphism (PCR-RFLP), as previously described in detail $(21,22)$. To detect deletions in GSTM1 and GSTT1 genes, a multiplex PCR was performed including $\beta$-globin gene amplification employed as a DNA sample control, as previously reported (15). 
I. Žuntar et al.: GSTP1, GSTM1 and GSTT1 genetic polymorphisms and total serum GST concentration in stable male COPD, Acta Pharm. 64 (2014) 117-129.

\section{Statistical analysis}

The frequency of each GST genotype and association between cases and controls were assessed by the $\chi^{2}$-test. Odds ratios (OR) and $95 \%$ confidence interval (CI) were used to describe the strength of association.

The influence of smoking histories (smokers, non-smokers and ex-smokers) on the AAT concentration and activity of GST and LDH in healthy individuals and COPD patients were tested with one way ANOVA and one way ANOVA on ranks (Kruskal Wallis test) for parametric and nonparametric data, respectively. Also, post hoc multiple comparisons were performed using the Holm-Sidak test (one way ANOVA) and Dunn's test (one way ANOVA on ranks).

The influence of GST genotypes (GSTP1, GSTM1 and GSTT1) on the serum GST activity in groups (COPD and healthy subjects) and in different genotype and smoking history groups were analyzed by two way ANOVA with post hoc comparisons (Holm-Sidak test).

The SigmaStat statistical program (version 3.5, SPSS Inc., Chicago, Illinois, USA) was used for all analyses except for odds ratio calculation by the MedCalc statistical program (version 7.0.0.2., MedCalc Software, B-9030, Mariakerke, Belgium). The value of $p<0.05$ was considered statistically significant.

\section{RESULTS AND DISCUSSION}

\section{GST and LDH activity and AAT concentration}

GST and LDH activity and AAT concentration levels (median and interquartile range) in healthy individuals and COPD patients subdivided according to their smoking histories are presented in Table I.

No statistically significant difference in GST activity between and within multiple groups was found. Unlike GST activities, the difference in AAT and LDH between and within groups reached statistical significance ( $p<0.05$, Table I, abbreviation marks a-d).

It is known that subjects with AAT deficiency have an increased risk of severe airflow obstruction and experience an accelerated lung function decline (23). In the present study, the total AAT value registered in COPD patients was higher than that registered in the controls and non-smoking controls in particular; both comparisons revealed statistically significant differences (Table I). Also, the value of COPD ex-smokers was significantly higher than the value for total controls as well as subgroups of healthy subjects (Table I). Interestingly, there were no significant differences between healthy smokers and COPD-smokers, and healthy non-smokers and COPD ex-smokers. Since AAT is known to be an acute phase protein, these results confirmed the existence of inflammation in stable COPD patients, but also implicated the complex mechanism in COPD development.

The significantly elevated LDH activity (Table I) seen in COPD was probably associated with chronic hypoxia and thus a higher supply of lactate posing as this enzyme's substrate, as suggested earlier (24). In other words, this rise in LDH activity might be at- 
I. Žuntar et al.: GSTP1, GSTM1 and GSTT1 genetic polymorphisms and total serum GST concentration in stable male COPD, Acta Pharm. 64 (2014) 117-129.

Table I. Glutathione S-transferase and lactate dehydrogenase activity, and alpha-1 antitrypsine concentration in healthy individuals and in COPD patients

\begin{tabular}{|c|c|c|c|c|}
\hline & & GST $\left(\mathrm{U} \mathrm{L}^{-1}\right)$ & AAT $\left(\mathrm{g} \mathrm{L}^{-1}\right)$ & $\mathrm{LDH}\left(\mathrm{U} \mathrm{L}^{-1}\right)$ \\
\hline & \multicolumn{4}{|c|}{ Median (interquartile range) } \\
\hline \multirow{4}{*}{$\begin{array}{l}\text { Healthy } \\
\text { subjects }\end{array}$} & $\begin{array}{c}\text { Total } \\
(n=60)\end{array}$ & $\begin{array}{c}69.00 \\
(54.00-80.25)\end{array}$ & $\begin{array}{c}1.54^{\mathrm{a}, \mathrm{b}} \\
(1.34-2.11)\end{array}$ & $\begin{array}{c}170.00^{\mathrm{d}} \\
(154.50-191.00)\end{array}$ \\
\hline & $\begin{array}{l}\text { Smokers } \\
(n=25)\end{array}$ & $\begin{array}{c}69.00 \\
(54.75-81.25)\end{array}$ & $\begin{array}{c}1.82 \\
(1.33-2.44)\end{array}$ & $\begin{array}{c}160.00^{\mathrm{d}} \\
(147.50-197.75)\end{array}$ \\
\hline & $\begin{array}{l}\text { Non-smokers } \\
\quad(n=19)\end{array}$ & $\begin{array}{c}67.00 \\
(52.75-79.00)\end{array}$ & $\begin{array}{c}1.46^{\mathrm{a}, \mathrm{b}} \\
(1.28-1.88)\end{array}$ & $\begin{array}{c}170.00^{\mathrm{d}} \\
(154.50-199.00)\end{array}$ \\
\hline & $\begin{array}{l}\text { Ex-smokers } \\
\quad(n=16)\end{array}$ & $\begin{array}{c}72.00 \\
(63.00-76.00)\end{array}$ & $\begin{array}{c}1.50^{\mathrm{b}} \\
(1.42-1.87)\end{array}$ & $\begin{array}{c}176.00^{\mathrm{d}} \\
(171.25-178.48)\end{array}$ \\
\hline \multirow{4}{*}{ COPD } & $\begin{array}{c}\text { Total } \\
(n=30)\end{array}$ & $\begin{array}{c}66.00 \\
(53.00-76.00)\end{array}$ & $\begin{array}{c}1.94^{\mathrm{a}} \\
(1.55-2.39)\end{array}$ & $\begin{array}{c}181.00^{\mathrm{d}} \\
(159.75-216.50)\end{array}$ \\
\hline & $\begin{array}{l}\text { Smokers } \\
(n=14)\end{array}$ & $\begin{array}{c}60.00 \\
(48.50-73.00)\end{array}$ & $\begin{array}{c}1.88 \\
(1.48-2.43)\end{array}$ & $\begin{array}{c}175.00^{c} \\
(142.00-191.00)\end{array}$ \\
\hline & $\begin{array}{l}\text { Non-smokers } \\
\quad(n=4)\end{array}$ & $\begin{array}{c}62.50 \\
(54.00-71.50)\end{array}$ & $\begin{array}{c}1.79 \\
(1.62-3.00)\end{array}$ & $\begin{array}{c}390.00^{c, d} \\
(233.25-531.75)\end{array}$ \\
\hline & $\begin{array}{l}\text { Ex-smokers } \\
\quad(n=12)\end{array}$ & $\begin{array}{c}70.00 \\
(58.50-90.75)\end{array}$ & $\begin{array}{c}1.98^{\mathrm{b}} \\
(1.59-2.40)\end{array}$ & $\begin{array}{c}198.50^{c, d} \\
(162.00-216.00)\end{array}$ \\
\hline
\end{tabular}

GST - glutathione S - transferase, LDH - and lactate dehydrogenase activity, AAT - alpha-1 antitrypsine, COPD - chronic obstructive pulmonary disease

a Significant difference between the groups (total COPD vs. control non-smokers, total COPD vs. total healthy subjects), $p<0.05$.

b Significant difference between the groups (COPD ex-smokers vs. healthy total, COPD ex-smokers vs. healthy non-smokers, COPD ex-smokers vs. healthy ex-smokers), $p<0.05$.

c Significant difference between the groups (COPD non-smokers vs. COPD smokers, COPD non-smokers vs. COPD ex-smokers), $p<0.05$.

d Significant difference between the groups (COPD total vs. healthy total, COPD total vs. healthy smokers, COPD total vs. healthy non-smokers, COPD non-smokers vs. healthy total, COPD non-smokers vs. healthy smokers, COPD non-smokers vs. healthy ex-smokers, COPD non-smokers vs. healthy non-smokers), $p<0.05$.

tributed to the facilitated lactate oxidation to pyruvate, which could be subsequently used in the tricarbon acid cycle for energy production. But, LDH showed a statistically significant difference within the group of COPD patients. Non-smokers revealed higher activity than smokers and ex-smokers, indicating that other factors, as well as inflammation and a complex mechanism are involved in increased LDH value of COPD subjects, regardless of the best-studied COPD risk factor smoking history.

\section{GSTP1, GSTM1 and GSTT1 genetic polymorphisms}

The results of genotype determination, along with those of allele frequency, are given in Table II. 
I. Žuntar et al.: GSTP1, GSTM1 and GSTT1 genetic polymorphisms and total serum GST concentration in stable male COPD, Acta Pharm. 64 (2014) 117-129.

Table II. Genotypic frequencies of GSTP1, GSTM1 and GSTT1 polymorphisms in older male Croats

\begin{tabular}{|c|c|c|c|c|}
\hline Genotype & $\begin{array}{l}\text { COPD } \\
(n=30)\end{array}$ & $\begin{array}{l}\text { Healthy sub- } \\
\text { jects }(n=60)\end{array}$ & $p$-value ${ }^{a}$ & $\begin{array}{c}\text { OR } \\
(95 \% \mathrm{CI})\end{array}$ \\
\hline \multicolumn{5}{|l|}{ GSTP1, exon 5, $n(\%)$} \\
\hline AA & $10(33)$ & $34(57)$ & & \\
\hline AG & $16(54)$ & $25(41)$ & & \\
\hline GG & $4(13)$ & $1(22)$ & 0.021 & $9.077(0.967-85.211)^{\mathrm{b}}$ \\
\hline$A G+G G$ & $20(67)$ & $26(43)$ & 0.062 & $2.615(1.048-6.529)^{\mathrm{c}}$ \\
\hline A/G allele freq. & $60 / 40$ & $78 / 22$ & 0.009 & \\
\hline HWE & 0.864 & 0.480 & & \\
\hline \multicolumn{5}{|l|}{ GSTP1, exon 6, $n(\%)$} \\
\hline $\mathrm{CC}$ & $2(3)$ & $25(42)$ & & \\
\hline $\mathrm{CT}$ & $21(73)$ & $25(42)$ & & \\
\hline $\mathrm{TT}$ & $7(24)$ & $10(16)$ & 0.003 & $1.522(0.514-4.503)^{\mathrm{b}}$ \\
\hline $\mathrm{CT}+\mathrm{TT}$ & $28(93)$ & $35(58)$ & 0.002 & $10.000(2.179-45.882)^{\mathrm{c}}$ \\
\hline $\mathrm{C} / \mathrm{T}$ allele freq. & $40 / 60$ & $63 / 37$ & 0.002 & \\
\hline HWE & 0.167 & 0.814 & & \\
\hline \multicolumn{5}{|l|}{ GSTM1, $n(\%)$} \\
\hline Present & $16(53)$ & $33(55)$ & & \\
\hline Null & $14(47)$ & $27(45)$ & 0.940 & $1.069(0.444-2.577)$ \\
\hline \multicolumn{5}{|l|}{ GSTT1, $n(\%)$} \\
\hline Present & $23(77)$ & $47(78)$ & & \\
\hline Null & $7(23)$ & $13(22)$ & 0.929 & $1.100(0.387-3.130)$ \\
\hline \multicolumn{5}{|c|}{ Combined GSTM1 and GSTT1 } \\
\hline Present/present & $14(46)$ & $31(52)$ & & $1.006(0.294-3.448)^{\mathrm{d}}$ \\
\hline Null/present & $9(30)$ & $16(27)$ & & \\
\hline Present/null & $2(7)$ & $2(3)$ & & \\
\hline Null/null & $5(17)$ & $11(18)$ & 0.816 & $1.222(0.508-2.939)^{\mathrm{e}}$ \\
\hline
\end{tabular}

COPD - chronic obstructive pulmonary disease, OR - odds ratio, HWE - Hardy-Weinberg equilibrium

a $p$-value of $\chi^{2}$-test

$\mathrm{b}$ GG vs. AA+AG and TT vs. CC+CT.

c GG+AG vs. AA and TT+CT vs. CC.

${ }^{\mathrm{d}} \mathrm{Null} /$ null vs. present/present

e Null/null+heterozygous (null/present and present/null) vs. present/present

The comparison of actual GSTP1 genotype distributions and those predicted by the $\chi^{2}$-test based on allele frequencies, showed the population covered by this study to be in Hardy-Weinberg equilibrium (HWE), indicating that the control and the COPD group 
I. Žuntar et al.: GSTP1, GSTM1 and GSTT1 genetic polymorphisms and total serum GST concentration in stable male COPD, Acta Pharm. 64 (2014) 117-129.

were sufficiently random and representative. The differences in GSTP1 exon 5, GSTP1 exon 6 and allele frequencies $(\mathrm{A} / \mathrm{G}$ and $\mathrm{C} / \mathrm{T}$ ) found in the control and COPD groups were statistically significant $(p=0.021, p=0.003, p=0.009$ and $p=0.002$, respectively). When compared to the wild AA genotype, the calculated relative risk for combined category of mutant GG and heterozygous AG genotypes did not reach statistical significance. Compared to the CC genotype, the odds ratio for the combined category of CT and TT genotypes was 10.000 (95\% CI 2.179-45.882) and reached statistical significance $(p=$ $0.002)$.

These results suggested that the mutant GSTP1 exon 5 genotype (GG) as well as mutant (TT) and joint genotypes of GSTP1 exon 6, mutant and heterozygous (TT+CT), could be genetic contributors to COPD susceptibility, while homozygous wild types (AA and CC) were not. Similarly, Lakhdar et al. (25) found the Tunisians carrying a GSTP1 Val105 allele were at higher COPD risk. In addition, the meta-analysis completed by Yan et al. (26) suggested that the GSTP1 105Val/Val genotype was an important genetic contributor to COPD susceptibility. In contrast, Yim et al. (13) showed no association between exon 5 and COPD in Koreans, while Ishii et al. (12) showed an increased prevalence of homozygous GSTP1 exon 5 wild type in Japanese COPD patients. Smolonska et al. $(27,28)$ reported that GSTP1 105 Val polymorphism had no COPD protective role in Asian population.

In the COPD group, the portion of null GSTM1 genotype carriers amounted to $47 \%$ compared to $45 \%$ in the controls. As regards the GSTT1 genotype, the percent share of null GSTT1 COPD-diagnosed carriers was $23 \%$ compared to $22 \%$ in the controls. The distribution of GSTM1 and GSTT1 genotypes in the COPD vs. controls was not significantly different. Calculated odds ratios for both genotypes were as follows: 1.069 for null GSTM1 and 1.100 for null GSTT1. The distribution of combined null GSTM1/GSTT1 genotypes and combined heterozygous (null/present and present/null) GSTM1/GSTT1 genotypes compared to combined both present GSTM1/GSTT1 genotypes was not significantly different.

A cohort study performed in Swiss general population showed a large proportion of Caucasians to carry one or both GST gene deletions (around $20 \%$ of GSTT1 gene deletion, around $50 \%$ GSTM1 gene deletion and around $10 \%$ of GSTT1/GSTM1 gene deletion carriers) (29). Similar results relative to null GSTT1, null GSTM1, and joint GSTM1/ GSTT1 null genotypes, were obtained in our study (Table II) as well. In the Korean (13) and Slovak populations (30), no association between GSTM1 and GSTT1 genetic polymorphism and COPD was found. In agreement with these findings, our results showed no association between GSTM1 and GSTT1 gene polymorphisms and COPD either. The paper by Mehrotra et al. (31) suggested that GSTT1, but not GSTM1 null genotype, might be associated with COPD susceptibility. A strong correlation between the EPHX1 113 mutant homozygote with lower bronchodilator responses in smoking-related COPD was found by Chen et al. (32).

Some research articles have shown the analysis of gene combination to be important for the estimation of gene-COPD relation. The study of Slovak population suggested the combination of the homozygous exon 3 mutant variant of EPHX1 gene and GSTM1 null genotype to be a significant predictor of increased COPD susceptibility, although none of the tested gene polymorphisms alone were associated with an increased COPD risk, at least not to a statistically significant extent (30). 
I. Žuntar et al.: GSTP1, GSTM1 and GSTT1 genetic polymorphisms and total serum GST concentration in stable male COPD, Acta Pharm. 64 (2014) 117-129.

He et al. (11) showed the combination of GSTT1 null genotype and GSTM1 and GSTP1 risk genotypes to be related to lung function impairments, while Lakhdar et al. (33) concluded that combined GSTM1, GSTT1, GSTP1 and EPHX1 genetic polymorphisms may have favourable effects on redox balance in COPD patients. Rodriguez et al. (14) found the modulating role of GSTP1 in COPD to take effect only in smokers lacking AAT. The study of Cheng et al. (9) proposed the combination of genetic variants including at least one mutant EPHX exon 3 allele, GSTM1 null and homozygous Ile105 GSTP1 genotypes to be a significant indicator of COPD susceptibility in Taiwanese population.

\section{The association between GST genotypes, total serum GST activity and smoking history}

Association between serum GST and different GST genotypes in COPD and healthy subjects were tested by two way ANOVA and presented in Figs. 1a-d.

Also, based on their genotypes, the tested subjects were divided into two groups: $(i)$ combined wild GST genotype consisting of GSTP1 exon 5 wild type/GSTP1 exon 6 wild type/GSTM1 present/GSTT1, and (ii) non-wild combined GST genotype consisting of all other genotypes, and compared for their total GST serum values. No combination of wild GST genotypes was found among COPD patients. Accordingly, no influence of combined wild GST genotypes (all wild type GST genotypes) as well as non-wild combined GST genotype on GST activity among different smoking history groups of COPD patients and controls was recorded, as seen in Fig. 1.

Wild type GST genetic combination was seen in more than 5 control subjects ( 2 smokers, 2 non-smokers, and 1 ex-smoker). Their GST activity was $85.50 \pm 16.29 \mathrm{U} \mathrm{L}^{-1}$ (median, $83 \mathrm{U} \mathrm{L}^{-1}$; range, $\left.69-107 \mathrm{U} \mathrm{L}^{-1}\right)$. In the remaining control subjects $(n=55 ; 23$ smokers, 17 non-smokers, and 15 ex-smokers), a combination of GST genotypes was found, their GST activity being $66.16 \pm 15.79 \mathrm{U} \mathrm{L}^{-1}$ (median, $67 \mathrm{U} \mathrm{L}^{-1}$; range, 38-111 $\mathrm{U} \mathrm{L}^{-1}$ ). Comparison of these two control subgroups yielded a statistically significant difference ( $p=0.023, t$-test), but this observation has no power and should be further clarified in a study involving a larger sample size. When comparing the non-wild GST genotype-carrying control and non-wild GST genotype-carrying COPD group members, no statistically significant difference was found by the $t$-test, nor in the comparison of the wild GST genotype-carrying control and the non-wild GST genotype-carrying COPD group.

The total GST activity seen in the controls and COPD group, as well as in smoking history-based (Table I) and GST genotype-based subgroups (Fig. 1), was not significantly different. In addition, the influence of different GST genotypes on GST activity among controls and COPD patients with different smoking history (smokers, ex-smokers and non-smokers) was not found in this study (Fig. 1). This is not surprising, since many GST genes regulate the enzyme production and,a single abnormality,may not be adequate to reduce the level of GST activity (34).

The Chinese study, which involved a similar number of controls but more COPD patients, showed that plasma GST activity was significantly higher in patients compared to controls, irrespective of their different genotypes (17). Also, that study concluded that polymorphisms of GSTT1, GSTM1 and GSTP1 genes were unlikely to be involved in the pathogenesis of COPD.

To the best of our knowledge, only one study reported GST activity measurements in the plasma of COPD patients together with determination of different GST genotypes 


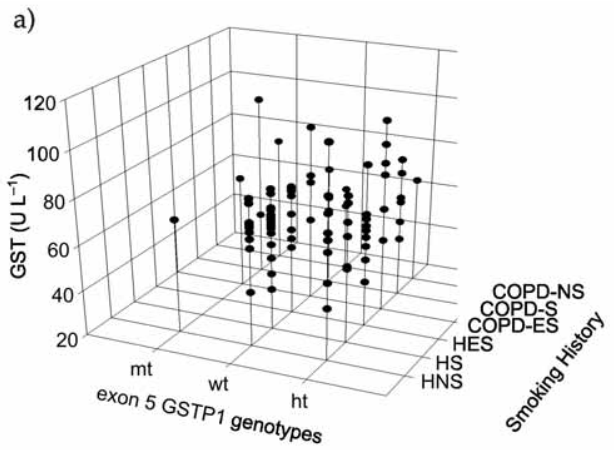

c)

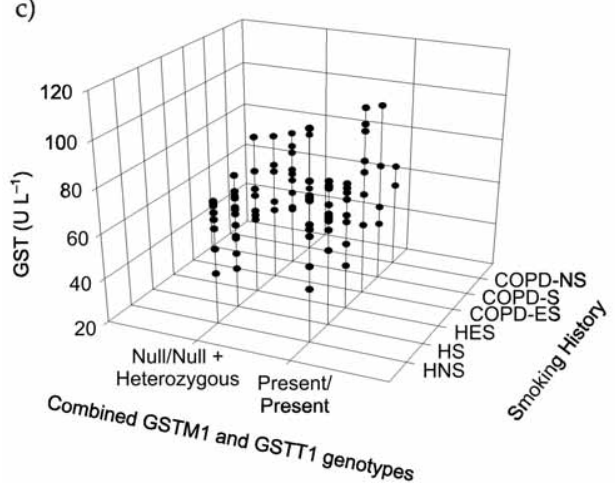

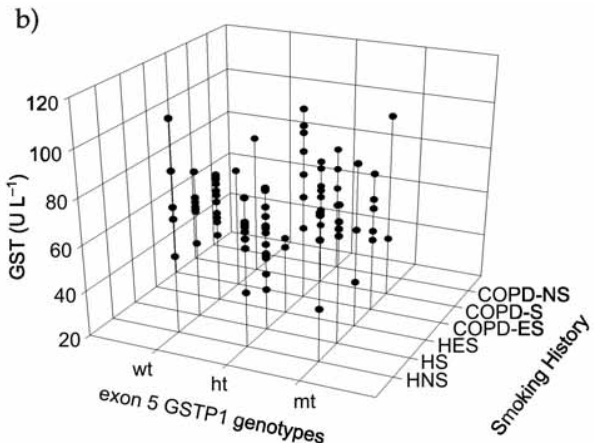

d)

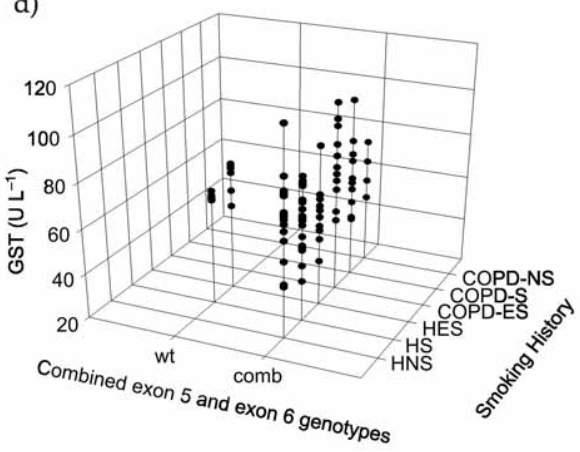

Fig. 1. Serum GST activity according to GSTP1: a) exon 5, b) exon 6, c) combined GSTM1 and GSTT1 and d) combined GSTP1 exon 5 and exon 6 genotypes in COPD patients and healthy subjects. Association between serum GST and different GST genotypes in COPD and healty subjects was performed by two way ANOVA. Statistical difference was not found $(p>0.05)$. wt - wild type genotype; $\mathrm{mt}$ - mutated homozygous genotype; ht - heterozygous genotype; comb - combined genotypes; HNS - healthy non-smokers; HS - healthy smokers; HES - healthy ex-smokers; COPD-NS - COPD non-smokers; COPD-S - COPD smokers; COPD-ES - COPD ex-smokers.

in smokers with or without COPD (17); thus the relative importance of GST in human lungs still remains unknown. In our study, serum GST activity seen in COPD patients was lower compared to the coresponding healthy controls, but the differences were not statistically significant (Table I). This trend of GST activity in the sera of patients with stable COPD could be probably explained by the drop of the GSH level in COPD and increased oxidative stress occuring in the lungs and systemically in COPD (1).

Recently, Bentley et al. (35) investigated the association of the variants of genes encoding antioxidant enzymes with the lung function phenotypes. They confirmed that single nucleotide polymorphisms (SNPs) in genes associated with glutathione synthesis and encoding glutathione S-transferases were associated with the lung function pheno- 
type. Also, their results supported a key role for the mitochondria and mitochondrial antioxidant enzymes in the lung and systemic response to ROS in cigarette smoke exposure.

Our results showed the presence of a systemic oxidant/antioxidant imbalance typical of COPD, with the measured parameters not being affected by smoking, so that we concluded that this imbalance was probably smoking independent.

One limitation of the present study was that only older male subjects were involved. However, it is known that COPD is more prevalent in those over the age of 60 and in men than in women. Another limitation was that this was a case-control study with a relatively small number of recruited subjects. However, the study groups were homogenous, sex and age matched controls and COPD subjects, with very well defined inclusion and exclusion criteria. Conclusions drawn from the study should be further supported and clarified by studies with larger sample sizes, including women and not only stable, but also exacerbating COPD patients.

\section{CONCLUSIONS}

Our study suggested that the GSTP1 mutant genotype of exon 5 (GG), and also GSTP1 mutant and heterozygous genotypes of exon 6 (TT and CT), could be genetic contributors to COPD susceptibility while null GSTM1, null GSTT1, joint GSTM1/GSTT1 null genotypes and wild type GSTP1 genotypes (AA and CC) were not. No influence of GST genotypes on serum GST activity in COPD subjects and controls subdivided according to smoking history was found.

According to our study results, cigarette smoking as one of the possible, but not indisputable COPD causal factors had no major and unequivocal impact on the serum level of GST, AAT and LDH, as there was no statistically significant difference between healthy subject subgroups divided according to their smoking history (non-smokers, ex-smokers and smokers).

In addition, an elevated and significantly higher level of AAT, known as an acute phase protein, was found in the group of COPD ex-smokers compared to healthy ex-smokers. As there were no significant differences between healthy smokers and COPD-smokers, and healthy non-smokers and COPD non-smokers, the results imply the complexity of the mechanism, not underlying the observed effects only inflammation and influence of smoking. Surprisingly, a significantly higher level of LDH was found in COPD non-smokers in comparison with COPD smokers and ex-smokers, but also in comparison with healthy control subgroups. These results supported hypoxia and inflammation as a part of the disease, but showed a complex causal mechanism and need for further investigations and clarifications.

Further studies are needed to clarify the role of genes, serum GST activity and smoking status in COPD onset; their sole and combined roles should be explored in a larger population group involving not only stable, but also exacerbating COPD patients.

Acknowledgments. - The authors thank Mrs Ana Malić and Mrs Vesna Boričević for technical assistance. This work was supported by the Ministry of Science, Education and Sports of the Republic of Croatia. 


\section{REFERENCES}

1. Global Strategy for the Diagnosis, Management, and Prevention of COPD, Global Initiative for Chronic Obstructive Lung Disease (GOLD) 2013, http://www.goldcopd.org/guidelines-global-strategy-for-diagnosis-management.html; last access date October 5, 2013.

2. B. Lamprecht, M. A. McBurnie, W. M. Vollmer, G. Gudmundsson, T. Welte, E. Nizankowska-Mogilnicka, M. Studnicka, E. Bateman, J. M. Anto, P. Burney, D. M. Mannino and S. A. Buist (BOLD Collaborative Research Group), COPD in never smokers: results from the population-based burden of obstructive lung disease study, Chest 139 (2011) 752-763; DOI: 10.1378/chest. 10-1253.

3. R. Lakhdar, S. Denden, A. Kassab, N. Leban, J. Knani, G. Lefranc, A. Miled, J. B. Chibani and A. H. Khelil, Update in chronic obstructive pulmonary disease: role of antioxidant and metabolizing gene polymorphisms, Exp. Lung. Res. 37 (2011) 364-375; DOI: 10.3109/01902148.2011. 580416.

4. R. C. Strange, M. A. Spiteri, S. Ramachandran and A. A. Fryer, Glutathione-S-transferase family of enzymes, Mutat. Res. 482 (2001) 21-26.

5. J. D. Hayes, J. U. Flanagan and I. R. Jowsey, Glutathione transferases, Annu. Rev. Pharmacol. Toxicol. 45 (2005) 51-88; DOI: 10.1146/annurev.pharmtox.45.120403.095857.

6. J. D. Hayes and D. J. Pulford, The glutathione S-transferase supergene family: regulation of GST and the contribution of the isoenzymes to cancer chemoprotection and drug resistance, Crit. Rev. Biochem. Mol. Biol. 30 (1995) 445-600.

7. K. Sundberg, A. S. Johansson, G. Stenberg, M. Widersten, A. Seidel, B. Mannervik and B. Jernström, Differences in catalytic efficiency of allelic variants of glutathione transferase P1-1 towards carcinogenic diol epoxides of polycyclic aromatic hydrocarbons, Carcinogenesis 19 (1998) 433-436.

8. D. J. Harrison, A. M. Cantlay, F. Rae, D. Lamb and C. A. Smith, Frequency of glutathione S-transferase M1 deletion in smokers with emphysema and lung cancer, Hum. Exp. Toxicol. 16 (1997) 356-360.

9. S. L. Cheng, C. J. Yu, C. J. Chen and P. C. Yang, Genetic polymorphisms of epoxide hydrolase and glutathione S-transferase in COPD, Eur. Respir. J. 23 (2004) 818-824; DOI: 10.1183/ 09031936.04.00104904.

10. J. J. Yim, G. Y. Park, C. T. Lee, Y. W. Kim, S. K. Han, Y. S. Shim and C. G. Yoo, Genetic susceptibility to chronic obstructive pulmonary disease in Koreans: combined analysis of polymorphic genotypes for microsomal epoxide hydrolase and glutathione S-transferase M1 and T1, Thorax 55 (2002) 121-125; DOI: 10.1136/thorax.55.2.121.

11. J. Q. He, J. Ruan, J. E. Connett, N. R. Anthonisen, P. D. Pare and A. J. Sandford, Antioxidant polymorphisms and susceptibility to a rapid decline in lung function in smokers, Am. J. Res. Crit. Care. Med. 166 (2002) 323-328; DOI: 10.1164/rccm.2111059.

12. T. Ishii, T. Matsuse, S. Teramoto, H. Matsui, M. Miyao, T. Hosoi, H. Takahashi, Y. Fukuchi and Y. Ouchi, Glutathione S-transferase P1 (GSTP1) polymorphism in patient with chronic obstructive pulmonary disease, Thorax 54 (1999) 693-696; DOI: 10.1136/thx.54.8.693.

13. J. J. Yim, C. G. Yoo, C. T. Lee, Y. W. Kim, S. K. Han and Y. S. Shim, Lack of association between glutathione S-transferase P1 polymorphism and COPD in Koreans, Lung 180 (2002) 119-125; DOI: $1007 /$ s004080000086.

14. F. Rodriguez, C. De La Roza, R. Jardi, M. Schaper, R. Vidal R and M. Miravitlles, Glutathione S-transferase P1 and lung function in patients with alpha(1)-antitrypsin deficiency and COPD, Chest 127 (2005) 1537-1543; DOI: 10.1378/chest.127.5.1537.

15. V. R. Arruda, C. E. Grignolli, M. S. Gonqalves, M. C. Soares, R. Menezes, S. T. Saad and F. F. Costa, Prevalence of homozygosity for the deleted alleles of glutathione S-transferase mu (GSTM1) and theta (GSTT1) among distinct ethnic groups from Brazil: relevance to environmental carcinogenesis?, Clin. Genet. 54 (1998) 210-214. 
16. S. L. Zhong, S. F. Zhou, X. Chen, X. Chan, S. Y. Chan, E. Chan, K. Y. Ng, W. Duan and M. Huang, Relationship between genotype and enzyme activity of glutathione S-transferase M1 and P1 in Chinese, Eur. J. Pharm. Sci. 28 (2006) 77-85; DOI: 10.1016/j.ejps.2006.01.002.

17. M. Chan-Yeung, S. P. Ho, A. H. Cheung, L. K. So, P. C. Wong, K. K. Chan, J. W. Chan, M. S. Ip and J. C. Mak, Polymorphisms of glutathione S-transferase genes and functional activity in smokers with or without COPD, Int. J. Tuberc. Lung. Dis. 11 (2007) 508-514.

18. J. G. Gea, M. Pasto, M. A. Carmona, M. Orozco-Levi, J. Palomeque and J. Broquetas, Metabolic characteristics of the deltoid muscle in patients with chronic obstructive pulmonary disease, Eur. Respir. J. 17 (2001) 939-945.

19. S. A. Miller, D. D. Dykes and H. F. Polesky, A simple salting out procedure for extracting DNA from human nucleated cells, Nucleic. Acids. Res. 16 (1988) 1215.

20. M. Habdous, M. Vincent-Viry, S. Visvikis and G. Siest, Rapid spectrophotometric method for serum glutathione S-transferase activity, Clin. Chim. Acta 326 (2002) 131-142; DOI: 10.1016/S0009- -8981(02)00329-7.

21. S. T. Saarikoski, A. Voho, M. Reinikainen, S. Anttila, A. Karjalainen, C. Malaveille, H. Vainio, K. Husrafvel-Pursiainen and A. Hirvonen, Combined effect of polymorphic GST genes on individual susceptibility to lung cancer, Int. J. Cancer. 77 (1998) 516-521.

22. I. Žuntar, S. Kalanj-Bognar, E. Topić, R. Petlevski, M. Štefanović and V. Demarin, The glutathione S-transferase polymorphisms in a control population and in Alzheimer's disease patients, Clin. Chem. Lab. Med. 42 (2004) 334-339; DOI: 10.1515/CCLM.2004.059.

23. A. T. Hill, E. J. Campbell, A. M. Ward and R. A. Stockley, Chronic obstructive pulmonary disease, with and without alpha-1-antitrypsin deficiency: management practices in the U.K., Respir. Med. 93 (1999) 481-490; DOI: 10.1016/S0954-6111(99)90091-4.

24. I. Čepelak, S. Dodig, D. Romić, N. Ruljančić, S. Popović-Grle and A. Malić, Enzyme catalytic activities in chronic obstructive pulmonary disease, Arch. Med. Res. 37 (2006) 624-629; DOI: 10.1016/ j.arcmed.2006.01.004.

25. R. Lakhdar, S. Denden, J. Knani, N. Leban, H. Daimi, M. Hassine, G. Lefranc, J. Ben Chibani and A. Haj Khelil, Relationship between glutathione S-transferase P1 polymorphisms and chronic obstructive pulmonary disease in a Tunisian population, Genet. Mol. Res. 9 (2010) 897-907; DOI: 10.4238/vol9-2gmr770.

26. F. Yan, C. Chen, J. Jing, W. Li, H. Shen and X. Wang, Association between polymorphism of glutathione S-transferase P1 and chronic obstructive pulmonary disease: a meta-analysis, Respir. Med. 104 (2010) 473-480; DOI: 10.1016/j.rmed.2010.01.009.

27. J. Smolonska, C. Wijmenga, D. S. Postma and H. M. Boezen, Erratum: Meta-analyses on suspected chronic obstructive pulmonary disease genes: a summary of 20 years' research, Am. J. Respir. Crit. Care. Med. 181 (2010) 765.

28. J. Smolonska, C. Wijmenga, D. S. Postma and H. M. Boezen, Meta-analyses on suspected chronic obstructive pulmonary disease genes: a summary of 20 years' research, Am. J. Respir. Crit. Care. Med. 180 (2009) 618-631; DOI: 10.1164/rccm.200905-07220C.

29. M. Imboden, S. H. Downs, O. Senn, G. Matyas, O. Brändli, E. W. Russi, C. Schindler, U. Ackermann-Liebrich, W. Berger and N. M. Probst-Hensch, (Sapaldia Team), Glutathione S-transferase genotypes modify lung function decline in the general population: SAPALDIA cohort study, Resp. Res. 8 (2007) 2-17; DOI: 10.1186/1465-9921-8-2.

30. J. Židzik, E. Slaba, P. Joppa, Z. Kluchova, P. Skyba, V. Habalova, J. Šalagovič and R. Tkačova, Glutathione S-transferase and microsomal epoxid hydrolase gene polymorphisms and risk of chronic obstructive pulmonary disease in Slovak population, Croat. Med. J. 49 (2008) 182-191; DOI: $10.3325 / \mathrm{cmj} .2008 .2 .182$. 
31. S. Mehrotra, A. Sharma, S. Kumar, S. Sardanaand J. K. Sharma, Polymorphism of glutathione S-transferase M1 and T1 gene loci in COPD, Int. J. Immunogen. 7 (2010) 263-267; DOI: 10.1111/ j.1744-313X.2010.00918.x.

32. C. Z. Chen, R. H. Wang, C. H. Lee, C. C. Lin, H. Y. Chang and T. R. Hsiue, Polymorphism of microsomal epoxide hydrolase is associated with chronic obstructive pulmonary disease and bronchodilator response, J. Med. Assoc. 110 (2011) 685-689; DOI: 10.1016/j.jfma.2011.09.003.

33. R. Lakhdar, S. Denden, M. H. Mouhamed, A. Chalgoum, N. Leban, J. Knani, G. Lefranc, A. Miled, J. Ben Chibani and A. H. Khelil, Correlation of EPHX1, GSTP1, GSTM1, and GSTT1 genetic polymorphisms with antioxidative stress markers in chronic obstructive pulmonary disease, Exp. Lung Res. 37 (2011) 195-204; DOI: 10.3109/01902148.2010.535093.

34. D. Sheehan, G. Meade, V. M. Foley and C. A. Dowd, Structure, function and evolution of glutathione transferases: implications for classification of non-mammalian members of an ancient enzyme superfamily, Biochem. J. 360 (2001) 1-16; DOI: 10.1042/0264-6021:3600001.

35. A. R. Bentley, S. B. Kritchevsky, T. B. Harris, A. B. Newman, D. C. Bauer, B. Meibohm, A. G. Clark and P. A. Cassano, Genetic variation in antioxidant enzymes and lung function, Free. Radic. Biol. Med. 52 (2012) 1577-1583; DOI: 10.1016/j.freeradbiomed.2012.02.025. 